\title{
A theranostic agent to enhance osteogenic and magnetic resonance imaging properties of calcium phosphate cements
}

Citation for published version (APA):

Ventura, M., Sun, Y., Cremers, S., Borm, P., Birgani, Z. T., Habibovic, P., Heerschap, A., van der Kraan, P. M., Jansen, J. A., \& Walboomers, X. F. (2014). A theranostic agent to enhance osteogenic and magnetic resonance imaging properties of calcium phosphate cements. Biomaterials, 35(7), 2227-2233. https://doi.org/10.1016/j.biomaterials.2013.11.084

Document status and date:

Published: 01/02/2014

DOI:

10.1016/j.biomaterials.2013.11.084

Document Version:

Publisher's PDF, also known as Version of record

Document license:

Taverne

Please check the document version of this publication:

- A submitted manuscript is the version of the article upon submission and before peer-review. There can be important differences between the submitted version and the official published version of record.

People interested in the research are advised to contact the author for the final version of the publication, or visit the DOI to the publisher's website.

- The final author version and the galley proof are versions of the publication after peer review.

- The final published version features the final layout of the paper including the volume, issue and page numbers.

Link to publication

\footnotetext{
General rights rights.

- You may freely distribute the URL identifying the publication in the public portal. please follow below link for the End User Agreement:

www.umlib.nl/taverne-license

Take down policy

If you believe that this document breaches copyright please contact us at:

repository@maastrichtuniversity.nl

providing details and we will investigate your claim.
}

Copyright and moral rights for the publications made accessible in the public portal are retained by the authors and/or other copyright owners and it is a condition of accessing publications that users recognise and abide by the legal requirements associated with these

- Users may download and print one copy of any publication from the public portal for the purpose of private study or research.

- You may not further distribute the material or use it for any profit-making activity or commercial gain

If the publication is distributed under the terms of Article 25fa of the Dutch Copyright Act, indicated by the "Taverne" license above, 


\title{
A theranostic agent to enhance osteogenic and magnetic resonance imaging properties of calcium phosphate cements
}

\author{
Manuela Ventura ${ }^{a}$, Yi Sun ${ }^{\mathrm{b}, \mathrm{c}}$, Sjef Cremers ${ }^{\mathrm{d}}$, Paul Borm ${ }^{\mathrm{d}}$, Zeinab T. Birgani ${ }^{\mathrm{e}}$, \\ Pamela Habibovic ${ }^{\mathrm{e}}$, Arend Heerschap ${ }^{\mathrm{b}}$, Peter M. van der Kraan ${ }^{\mathrm{f}}$, John A. Jansen ${ }^{\mathrm{a}, *}$, \\ X. Frank Walboomers ${ }^{a}$ \\ a Department of Biomaterials, Radboud University Nijmegen Medical Centre, PO Box 9101, 6500 HB Nijmegen, The Netherlands \\ ${ }^{\mathrm{b}}$ Department of Radiology, Radboud University Nijmegen Medical Centre, PO Box 9101, 6500 HB Nijmegen, The Netherlands \\ ${ }^{c}$ Department of Urology, Radboud University Nijmegen Medical Centre, PO Box 9101, 6500 HB Nijmegen, The Netherlands \\ ${ }^{\mathrm{d}}$ Nano4Imaging GmbH, Zentrum für Biomedizintechnik (ZBMT), Pauwelsstrasse 17, 52074 Aachen, Germany \\ ${ }^{\mathrm{e}}$ Department of Tissue Regeneration, University of Twente, MIRA Institute for Biomedical Technology and Technical Medicine, PO Box 217, 7500 AE \\ Enschede, The Netherlands \\ ${ }^{\mathrm{f}}$ Department of Rheumatology, Radboud University Nijmegen Medical Centre, PO Box 9101, 6500 HB Nijmegen, The Netherlands
}

\section{A R T I C L E I N F O}

Article history:

Received 12 November 2013

Accepted 27 November 2013

Available online 14 December 2013

\section{Keywords:}

Bone tissue engineering

Calcium phosphate cement

BMP (bone morphogenetic protein)

Drug delivery

MRI (magnetic resonance imaging)

\begin{abstract}
A B S T R A C T
With biomimetic biomaterials, like calcium phosphate cements (CPCs), non-invasive assessment of tissue regeneration is challenging. This study describes a theranostic agent (TA) to simultaneously enhance both imaging and osteogenic properties of such a bone substitute material. For this purpose, mesoporous silica beads were produced containing an iron oxide core to enhance bone magnetic resonance (MR) contrast. The same beads were functionalized with silane linkers to immobilize the osteoinductive protein BMP-2, and finally received a calcium phosphate coating, before being embedded in the CPC. Both in vitro and in vivo tests were performed. In vitro testing showed that the TA beads did not interfere with essential material properties like cement setting. Furthermore, bioactive BMP-2 could be efficiently released from the carrier-beads. In vivo testing in a femoral condyle defect rat model showed long-term MR contrast enhancement, as well as improved osteogenic capacity. Moreover, the TA was released during CPC degradation and was not incorporated into the newly formed bone. In conclusion, the described TA was shown to be suitable for longitudinal material degradation and bone healing studies. (c) 2013 Elsevier Ltd. All rights reserved.
\end{abstract}

\section{Introduction}

The growing need for bone treatment procedures keeps a high pressure on the development and optimization of artificial substitutes for bone regeneration. Calcium phosphate (CaP) based materials are amongst the most commonly used, as they closely resemble structure and composition of the natural bone. Especially, injectable CaP-based cements (CPCs) have the advantage of optimal bone defect filling capacity, and are applicable through minimally invasive surgery [1]. The osteoinductivity of such materials can be enhanced by incorporating biologically active molecules, like BMP2 , either via adsorption onto pre-set CPC scaffolds [2], or via loading before the CPC setting.

At the same time, assessment of tissue regeneration is essential to optimize the stages of bone healing. Most commonly, bone

\footnotetext{
* Corresponding author. Tel.: +31243614006.

E-mail addresses: John.Jansen@radboudumc.nl,_j.jansen@dent.umcn.nl (J.A. Jansen).
}

healing is assessed with X-ray or computed tomography (CT) assessments. Recently, also zero echo time (ZTE) magnetic resonance imaging (MRI) [3], has proved to be a powerful tool for bone tissue imaging. However, all commonly used techniques for bone imaging lack sensitivity to detect the presence of synthetic bone substitutes, without additional contrast enhancement. Advances in the fields of material science, imaging and formulation development lead to the development of theranostics, which aims at combining both therapeutic (e.g. the BMP-2) and diagnostic (e.g. the MR detection) functions within a single product. Theranostic medicine is currently explored to enhance the quality of cancer treatments, atherosclerosis, infections, and a variety of regenerative medicine applications [4]. In this study, we have developed a theranostic agent (TA), a silica-based nanocomposite MR contrast agent, which also functions as carrier for BMP-2 release. The specific formulation of such a composite, combined with the biocompatibility of silica, is meant to provide imaging contrast enhancement, while reducing unspecific reactivity and improving the osteogenic performance of CPCs. After 
in vitro characterization, the developed TA was tested in vivo, in a femoral condyle defect model in rats. Imaging properties were monitored by MRI, while osteogenic performance was measured by histomorphometry, up to 8 weeks post-implantation.

\section{Materials and methods}

\subsection{CaP cement with PLGA microspheres}

Calcium phosphate cement consisted of $85 \%$ of $\alpha$-tricalcium phosphate, $10 \%$ dicalcium phosphate dihydrate and $5 \%$ hydroxyapatite [5]. The cement powder was sterilized using gamma radiation with $25 \mathrm{kGy}$ (Isotron B.V., Ede, The Netherlands). As a porogen, acid-terminated PLGA microparticles were prepared using a doubleemulsion solvent-extraction technique. Poly (DL-lactic-co-glycolic acid), (PURASORB, Purac, Gorinchem, The Netherlands) with a lactic to glycolic acid ratio of 50:50 and an average molecular weight of $4.55 \pm 0.03 \mathrm{kDa}$, was used for microparticle preparation. The average size of the microparticles, as determined with image analysis, was $96 \pm 16 \mu \mathrm{m}$ [6]. PLGA microparticles were mixed with the CaP cement powder in a proportion of $20 \% \mathrm{wt} / \mathrm{wt}$.

\section{Theranostic agent}

A customized theranostic agent (TA) was synthesized. The contrast agent particles were prepared by an inverse emulsion approach (patent WO2005/052581; Nano4Imaging $\mathrm{GmbH}$, Aachen, Germany) using MRI responsive ultra small iron particles (USPIO) embedded within a mesoporous silica matrix. Two contrast agent formulations were tested: (i) MRI- 1 with an iron oxide core size range of 200$300 \mathrm{~nm}$ at an end concentration of $40 \% \mathrm{wt} / \mathrm{wt}$, and (ii) MRI- 2 with an iron oxide core size range between 0.5 and $1.2 \mu \mathrm{m}$ at an end concentration of $30 \% \mathrm{wt} / \mathrm{wt}$.

BMP-2 (Pfizer, InductOs ${ }^{\circledR}$ former Wyeth Europe Ltd., Berkshire, UK) was immobilized onto the surface of the beads, functionalized with silane linkers carrying amino functions (3-aminopropyl-trimethoxysilane), as described by Elhert et al. [7]. A solution containing $10 \mu \mathrm{g}$ of BMP-2 was mixed with a suspension of beads (12.5 $\mu \mathrm{L}$ at a concentration of $20 \mathrm{mg} / \mathrm{mL}$ ) in phosphate-buffered saline (PBS) buffer (pH 6.8). PBS was then removed and the beads were resuspended in $50 \mathrm{~mm} 2-(\mathrm{N}-$ morpholino)ethanesulfonic acid (MES) buffer ( $\mathrm{pH} 5.5$ ) and placed at $4{ }^{\circ} \mathrm{C}$, overnight

Finally, the TA beads were given a calcium phosphate coating. For this, $500 \mu \mathrm{L}$ of a $5 \mathrm{mg} / \mathrm{mL}$ contrast agent suspension, containing $10 \mu \mathrm{g}$ of BMP-2, was mixed with $54 \mu \mathrm{L}$ of $40 \mathrm{~mm} \mathrm{CaCl}_{2}, 77 \mu \mathrm{L}$ of $3.9 \mathrm{~mm} \mathrm{Na}_{2} \mathrm{HPO}_{4}$ and $60 \mu \mathrm{L}$ of $1 \mathrm{~mm} \mathrm{NH}_{3}$. The mixture was placed at $4{ }^{\circ} \mathrm{C}$ for $1 \mathrm{~h}$. After $\mathrm{pH}$ had reached 7.9, $60 \mu \mathrm{L}$ of $1 \mathrm{~mm} \mathrm{NH}_{3}$ was added into the solution, and again placed at $4{ }^{\circ} \mathrm{C}$ for $1 \mathrm{~h}$. When $\mathrm{pH}$ was 8.5 , again $80 \mu \mathrm{L} 1 \mathrm{~mm}$ $\mathrm{NH}_{3}$ was added and the solution remained at $4{ }^{\circ} \mathrm{C}$ for $1.5 \mathrm{~h}$. The final $\mathrm{pH}$ was 9.5 . The suspension was maintained under continuous rotation throughout the entire procedure. The resulting coated beads were magnetically separated and washed 4 times in PBS. The precipitate was then diluted to an end concentration of $20 \mathrm{mg} / \mathrm{mL}$. Control samples were treated the same way, with exception that the beads did not contain BMP-2. After freeze-drying, the obtained solid phase was then mixed to reach a final end concentration of $0.1 \%(\mathrm{wt} / \mathrm{wt}$ ) within the bone cement/PLGA composite.

\subsection{Composite preparation}

The cement was created by adding a filtered sterilized ( $0.2 \mu \mathrm{m}$ filter $) 2 \%$ aqueous solution of sodium phosphate $\left(\mathrm{Na}_{2} \mathrm{HPO}_{4}\right)$ to the PLGA/CaP or PLGA/CaP/TA powder mixture using a 2-mL syringe (BD Plastipak, Becton Dickinson S.A., Madrid, Spain) with a closed tip. The components were shaken for $20 \mathrm{~s}$ using a mixing apparatus (Silamat Vivadent, Schaan, Liechtenstein).

\subsection{Characterization of $C P C$ and $T A$}

\subsubsection{Theranostic agent-beads}

The morphology of the TA beads was determined by SEM and transmission electron microscopy (TEM). SEM images were obtained at $2000 \times, 5000 \times$ and $10,000 \times$ magnification, while TEM images were obtained at $30 \mathrm{~K}$ and $50 \mathrm{~K}$.

Elemental analysis was performed using a scanning electron microscope (SEM, Philips XL30, Eindhoven, The Netherlands) coupled with an energy dispersive X-ray spectrometer (EDS, EDAX, AMETEK Materials Analysis Division, Mahwah, NJ). Samples were sputtered with a thin layer of gold using a common sputtering instrument (Cressington 108A, Watford, UK) to improve the surface conductivity. The EDS elemental maps were taken at accelerating voltage of $15 \mathrm{KeV}$ and working distance of $10 \mathrm{~mm}$.

\subsection{2. $C P C$}

Initial and final setting times for the different cement formulations were assessed using custom available Gillmore needles (ASTM C266). A plastic mould of $3 \mathrm{~mm}$ (diameter) $\times 6 \mathrm{~mm}$ (height) was used to prepare the scaffolds. Both initial and final setting times were determined and tests were performed at room temperature. Thereafter, for mechanical testing samples were placed on an 858 MiniBionixII ${ }^{\circledR}$ testing bench (MTS, Eden Prairie, MN) and the compressive strength in the longitudinal direction of the specimens was measured at $0.5 \mathrm{~mm} / \mathrm{min}$ cross-head speed. Finally, to assess morphology all different cement formulations were assessed by

\section{Table 1}

Experimental groups and implantation scheme. With the aim of testing both the MR contrast agent and BMP-2 performance, four experimental groups were selected: (i) Empty - untreated defect, (ii) CPC - defect filled with injectable calcium CPC, (iii) MRI - defect filled with injectable CPC incorporating the MR contrast agent and (iv) MRI/BMP2 - defect filled with injectable CPC incorporating the MR contrast agent and BMP-2.

\begin{tabular}{lll}
\hline Rat & Right defect & Left defect \\
\hline 1 & Empty & CPC \\
2 & CPC & MRI \\
3 & MRI & MRI/BMP2 \\
4 & MRI/BMP2 & Empty \\
5 & Empty & CPC \\
6 & CPC & MRI \\
7 & MRI & MRI/BMP2 \\
8 & MRI/BMP2 & Empty \\
9 & Empty & CPC \\
10 & MRI/BMP2 & MRI \\
\hline
\end{tabular}

scanning electron microscopy (SEM). For this purpose, destructed samples were obtained from the compression test. Images were obtained at $500 \times, 1000 \times$ and $2000 \times$ magnification.

\subsection{Ex vivo MRI}

Sixteen explanted rat femoral condyles were collected, which were left-over material from unrelated experiments (RU-DEC 2012-317). In each condyle, a cylindrical defect was made of $3.0 \mathrm{~mm}$ depth and diameter; and filled bearing either the contrast agent MRI- 1 or MRI- 2 mixed into the CPC, at a concentration of both 0.1 and $0.5 \% \mathrm{wt} / \mathrm{wt}$ ( $n=4$ for each condition). After $30 \mathrm{~min}$, condyles were immersed in $70 \%$ ethanol and MR imaging was performed on a 11.7T MR system (Biospec, Bruker, Germany) with a mouse brain surface coil. Zero echo time (ZTE) images were acquired for all samples at the same time and settings, to avoid confounding effects of individual calibration or thresholding, at $200 \mathrm{kHz}$ bandwidth, TR $=4 \mathrm{~ms}$, flip angle $=5^{\circ}, \mathrm{FOV}=50 \times 50 \times 50 \mathrm{~mm}$, matrix size $128 \times 128 \times 128$, total acquisition time $3.27 \mathrm{~min}$

\subsection{BMP-2 immobilization and release}

Following BMP-2 immobilization, the amount of BMP-2 effectively bound to the surface of the beads was measured. Thereafter, BMP-2 release tests were performed and the protein concentration was measured by both ELISA, to quantify all released BMP-2, and BRE-Luc assay, to specifically quantify the fraction of bioactive BMP-2.

\subsubsection{Quantification of effectively bound BMP-2}

The fraction of BMP-2 bound to the silica beads was determined by enzymelinked immunosorbent assay ELISA assays, with a Quantikine ${ }^{\circledR}$ BMP-2 immunoassay kit (R\&D Systems, Minneapolis, MN) following the manufacturer's instructions. The assay was performed for all process steps, i.e. (i) on the MES buffer used for the immobilization, and removed during the first washing step, (ii) on the PBS collected after the following washing steps, and finally (iii) on the resulting beads.

\subsubsection{Quantification of released BMP-2}

A $12.5 \mu \mathrm{L}$ aliquot of the bead suspensions, loaded with BMP-2 was resuspended in $500 \mu \mathrm{L}$ of minimum essential medium alpha (MEM- $\alpha$ ). Both coated and noncoated samples remained in the medium for $2 \mathrm{~h}, 3$ days and 7 days. The amount of BMP-2 released into the supernatants was determined using ELISA (R\&D Systems) and BRE-Luc assay, described below.

\subsubsection{BRE-Luc assay}

M3T3-BRE-Luc cells were cultured in Dulbecco's modified eagle's medium (DMEM) containing $5 \%$ fetal bovine serum (FBS) and $800 \mu \mathrm{g} / \mathrm{mL}$ neomycine, at $37{ }^{\circ} \mathrm{C}$ in a humidified atmosphere of $5 \% \mathrm{CO}_{2}$. Cells were trypsinized and seeded at a concentration of $2 \times 10^{4}$ in $100 \mu \mathrm{L}$ of $5 \%$ FCS-DMEM in a flatbottomed transparent plate for $24 \mathrm{~h}$. After removing the culture medium, $100 \mu \mathrm{L}$ of the samples medium, containing the released BMP-2, were added into the wells, together with $2 \%$ FBS. To estimate BMP-2 release, a standard curve obtained with soluble BMP-2 in dilutions from 0.4 until $50 \mathrm{ng} / \mathrm{mL}(100 \mu \mathrm{L} /$ well $)$ was performed in parallel. Following the incubation time of $16-20 \mathrm{~h}$, the medium was removed and replaced by $25 \mu \mathrm{L}$ of reporter lysis buffer (Promega, Madison, WI). The incubation was done at $-80^{\circ} \mathrm{C}$ for at least $1 \mathrm{~h}$. After defrosting, $25 \mu \mathrm{L}$ of Bright glow (Promega) were added to each well and the luciferase intensity was measured (LUMIstar Omega, BMG LABTECH GmbH, Ortenberg, Germany). 

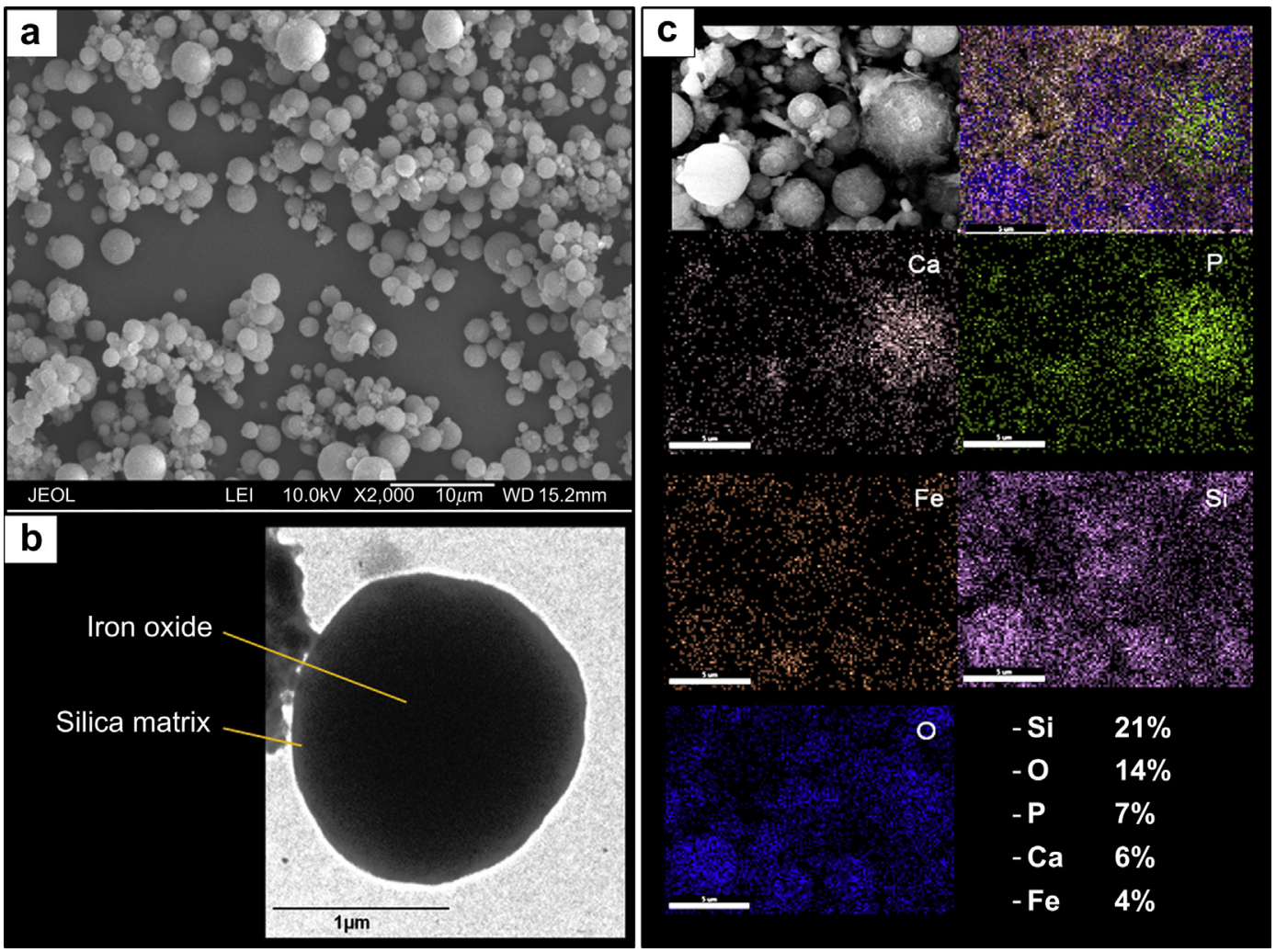

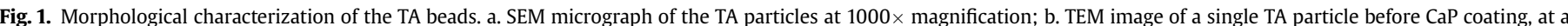

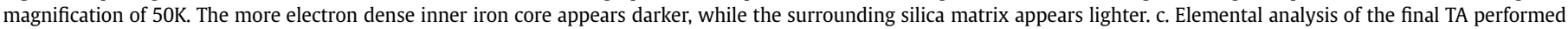

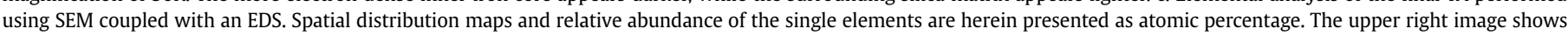
the overlap of all detected elements.

\subsection{In vivo assays}

\subsubsection{Animal model}

All in vivo work was conducted in accordance with standards and protocols of the Radboud University Medical Center, Nijmegen, The Netherlands. National guidelines for care and use of laboratory animals were obeyed and approval of the Experimental Animal Ethical Committee was obtained (RU-DEC 2012-060). Ten healthy adult male Wistar rats, weighing 250-300 g were included as experimenta animals. Surgery was performed under general inhalation anesthesia (Isoflurane) and aseptic conditions. For the surgical procedure animals were immobilized and both legs were shaved, washed and disinfected. The knee joint was exposed after a longitudinal parapatellar incision. At the femoral intercondylar notch, a cylindrical defect (3.0 mm depth and diameter) was then prepared using a dental bur and continuous external cooling with saline. Defects were filled with the various CPC materials, or left untreated in control animals (Table 1), before the subcutaneous tissue and skin were closed by suturing in layers. In vivo MR scans were performed 4 and 8 weeks post-surgery. Thereafter, animals were sacrificed and histology and micro-CT were performed.

\subsubsection{In vivo $M R I$}

MR imaging was performed 4 and 8 weeks after surgery using a 11.7T MR system (Biospec, Bruker, Germany) with a home-built bare Helmholtz coil with a size of $3 \times 3 \mathrm{~cm}$. Zero echo time imaging was performed at $200 \mathrm{kHz}$ bandwidth, TE/ $\mathrm{TR}=0 \mathrm{~ms} / 8 \mathrm{~ms}$, flip angle $=5^{\circ}, \mathrm{FOV}=50 \times 50 \times 50 \mathrm{~mm}$, matrix size: $128 \times 128 \times 128,4$ averages and a final acquisition time of $30.27 \mathrm{~min}$.

\subsection{Micro-CT}

Eight weeks after surgery, the animals were sacrificed by $\mathrm{CO}_{2} / \mathrm{O}_{2}$ overdose Femoral condyles were retrieved and surrounding soft tissue was removed. Bone samples were fixed in $10 \%$ formalin for $48 \mathrm{~h}$ and subsequently transferred to $70 \%$ ethanol for the duration of the $\mu \mathrm{CT}$ scans. For 3D analysis, the specimens were placed vertically onto the sample holder of a micro-CT imaging system (Skyscan 1072, Kontich, Belgium). Subsequently, samples were recorded at a $11.10 \mu \mathrm{m}$ resolution (Xray source $100 \mathrm{kV} / 98 \mu \mathrm{A}$; Exposure time $3.9 \mathrm{~s} ; 1 \mathrm{~mm}$ filter applied). Then, using NRecon V1.4 (SkyScan), a cone beam reconstruction was performed on the projected files. Finally, 3D-reconstructions of the samples were obtained (3D-DOCTOR 4.0, Able Software Corp, Lexington, MA).

\subsection{Histology}

After scanning, all specimens were decalcified for $72 \mathrm{~h}$ in 10\% ETDA. Samples were then dehydrated in gradual series of ethanol $(70 \%-100 \%)$ and embedded in Paraffin. Sections of $6 \mu \mathrm{m}$ thickness were cut in a plane parallel to the long axis of the femur using a Leica RM2165 Microtome (Leica Microsystems, Rijswijk, The Netherlands). The sections were stained with haematoxylin/eosin and trichrome Elastin van Gieson (EVG); at least six sections of each specimen were analyzed.

\subsection{Bone quantification}

The EVG-stained slides were quantitatively assessed using computer-based image analysis techniques (Leica Qwin Pro-image, Leica, Wetzlar, Germany). From digitalized images (magnification $2.5 \times$ ), the percentage of bone tissue was determined within the area of interest, positioned accordingly to the original size and position of the created defect.

\subsection{Statistical analysis}

Statistical analysis for bone quantification was performed using GraphPad Instat ${ }^{\circledR}$ (GraphPad Software, San Diego, CA). Statistical comparisons were performed by one-way analysis of variance with a Tukey multiple comparison post-test. For setting time and compression tests, data are presented as mean \pm standard deviation and significant differences were determined by analysis of variance (ANOVA). All differences were considered significant at $P$-values $<0.05$.

\section{Results}

\subsection{Characterization of TA beads}

As evident from the SEM micrographies, the beads presented a uniform size distribution (Fig. 1a), with a mean value of $1.68 \pm 0.86$ for MRI- 1 and $1.65 \pm 0.78 \mu \mathrm{m}$ for MRI-2. From the TEM image it was possible to identify the inner iron core which appears darker, as more electron dense, surrounded by the silica matrix (Fig. 1b). As shown in Fig. 1c, five principal elements could be detected: silicon 
( $\mathrm{Si}$ ) and oxygen $(\mathrm{O})$ as components of the silica matrix, phosphorus $(\mathrm{P})$ and calcium $(\mathrm{Ca})$ from the most superficial coating layer, and iron (Fe) from the inner core. The spatial distribution of Fe, $\mathrm{O}$ and $\mathrm{Si}$ was homogeneous throughout the entire field of view, delimited by the SEM micrography. Differently, despite being well-distributed throughout the whole sample, presence of $\mathrm{Ca}$ and $\mathrm{P}$ showed evident variability even within the single beads.

\subsection{Characterization of CPC/TA}

All formulations showed a uniformly distributed appearance of the TA within the cement powder (Fig. 2a). At both the 0.1 and $0.5 \%$

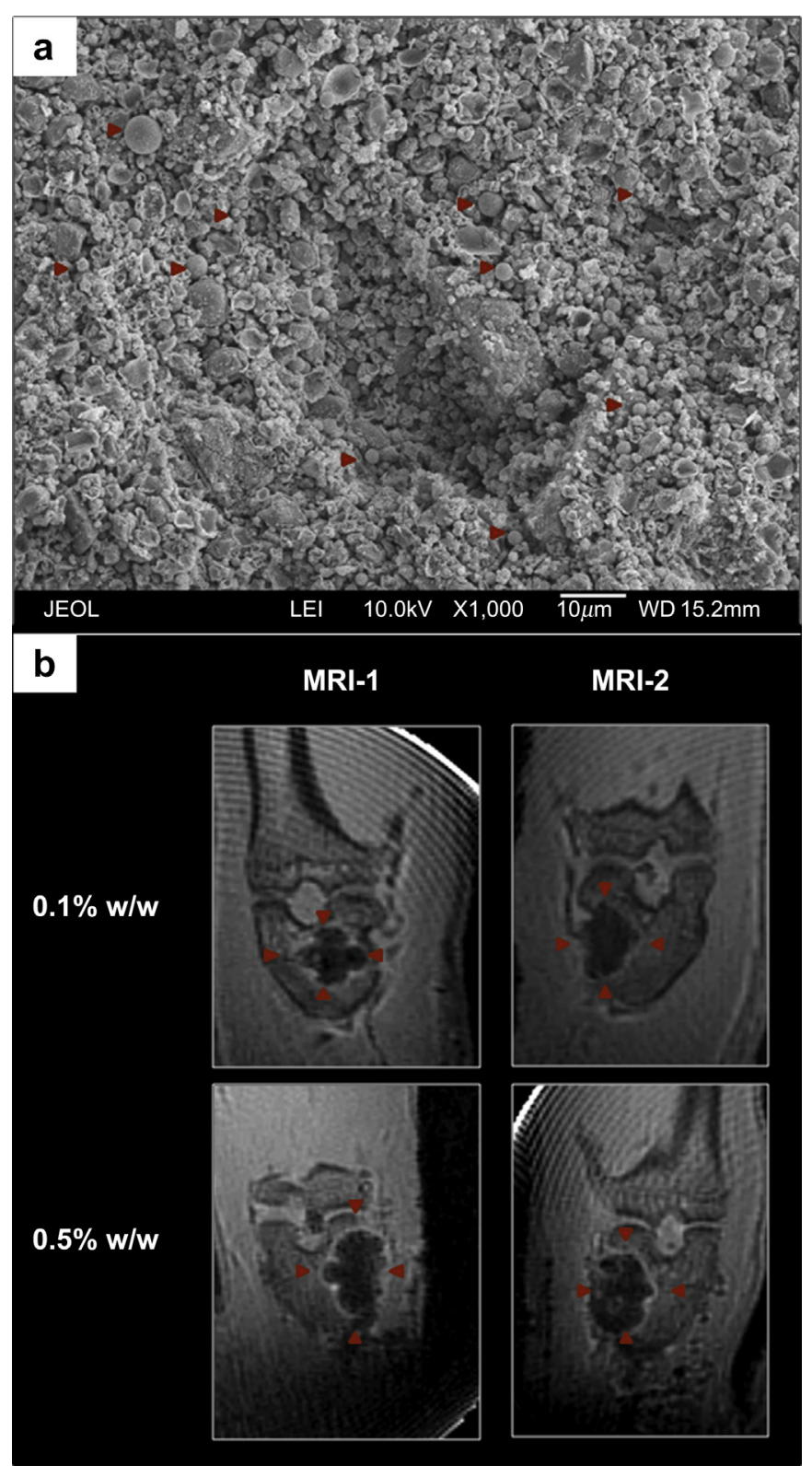

Fig. 2. Characterization of $\mathrm{CPC} / \mathrm{TA}$ composite. a. SEM micrograph of TA particles (indicated by red arrows) mixed within the CPC matrix at $1000 \times$ magnification. Note that the TA is uniformly distributed within the cement matrix. b. Ex vivo MR imaging performance of smaller diameter/higher concentration MRI-1 vs. larger diameter/lower concentration MRI-2 agents, at two different concentrations. Note that $0.1 \% \mathrm{w} / \mathrm{w}$ MRI-2 was the optimal combination providing MR-contrast enhancement. (For interpretation of the references to color in this figure legend, the reader is referred to the web version of this article.) wt/wt concentrations, no differences were measured in initial or final setting time with the incorporation of MRI-1. The addition of MRI-2 caused a significant increase of the final setting time from approximately $18-20 \mathrm{~min}$. When assessing the material compression strength, only the highest concentration of MRI-2 caused a significant decrease (Table 2).

\subsection{Ex vivo MRI}

Obvious CPC-to-bone contrast enhancement was seen in all samples. For the MRI-1 formulation with a lower core diameter, yet higher iron concentration, contrast was mostly characterized by the presence of a so-called blooming artifact. Further, at the settings used both applied concentrations led to a considerable visual overestimation of the size, with regards to the original defect perimeter. In contrast, the higher core diameter, lower iron concentration MRI-2 formulation proved to be optimal, as by visual inspection the contrast enhancement was corroborating closely with the original defect morphology (Fig. 2b). Based on this evidence, MRI-2 at a concentration of $0.1 \% \mathrm{wt} / \mathrm{wt}$ was selected only for the following tests and the final in vivo evaluation.

\subsection{BMP-2 immobilization and release}

The amount of BMP-2 immobilized on the surface of the beads was measured by ELISA. The assay showed that it was possible to immobilize relatively high amounts of BMP-2 on the substrates using an aminosilane linker. The measured amount was about $4.97 \pm 0.86 \mu \mathrm{g}$ of BMP-2 per $12.5 \mu \mathrm{L}$ bead suspension, i.e. approximately $50 \%$ of the originally added $10 \mu \mathrm{g}$.

The remaining $1.98 \pm 0.72 \mu \mathrm{g}$ were measured in the supernatant and $2.54 \pm 1.81$ in the washing medium.

To quantify the released BMP-2 and its biological activity, the complementary ELISA and BRE-Luc tests were carried out. Both detection methods showed a progressive release during the observational period of 7 days. The presence of the hydroxyapatite coating induced a double amount of growth factor to be released after both 3 and 7 days, compared to the non-coated beads (Fig. 3a). BRE-Luc data (Fig. 3b) showed that at least half of the released protein measured by ELISA remained biologically active.

\subsection{In vivo MRI}

The surgical procedure did not lead to any adverse and unexpected reactions. All animals recovered within a few hours postsurgery and none were restricted in their movements. Rats were monitored during the whole experimental period and no evident signs of discomfort nor weight loss were observed. Eight weeks post-implantation, all femoral condyles were retrieved. At a macroscopical visual inspection, no clear differences were observed between the Empty, CPC and MRI groups, whereas obvious areas of new bone formation were detected in the group containing BMP-2.

MR images obtained 4 weeks post-implantation showed a partial healing of the untreated bone defects, which appeared to be progressed at week 8 . No reliable observations could be made within the CPC group without additives, as the implanted material could not be reliably localized among the surrounding natural bone at either time point. In contrast, the incorporation of the MRI-2 contrast agent provided information about the correct localization of the injected material. Interestingly, also one undesired event could immediately be found, i.e. the formation of an evident crack in the center of one of the implanted cements. In this group, the MRI-2 contrast enhancement could still be detected 8 weeks following the implantation. Finally, similar contrast was observed at 4 weeks in the presence of the MRI-2/BMP-2 sample. This 
Table 2

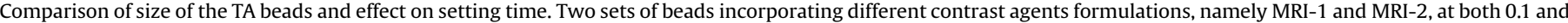
$0.5 \% \mathrm{w} / \mathrm{w}$ concentrations, were tested $\left({ }^{*}=P<0.05\right)$.

\begin{tabular}{|c|c|c|c|c|c|}
\hline Sample & $\begin{array}{l}\text { Core size } \\
(\mu \mathrm{m})\end{array}$ & $\begin{array}{l}\text { Total size } \\
(\mu \mathrm{m})\end{array}$ & $\begin{array}{l}\text { Initial setting } \\
\text { time (min) }\end{array}$ & $\begin{array}{l}\text { Final setting } \\
\text { time (min) }\end{array}$ & Mechanical loading $(N)$ \\
\hline $\mathrm{CPC}$ & - & - & $3.91 \pm 0.22$ & $17.94 \pm 0.44$ & $75.99 \pm 20.51$ \\
\hline MRI-1 0.1\% w/w & $0.2-0.3$ & $1.68 \pm 0.86$ & $3.94 \pm 0.36$ & $18.64 \pm 0.43$ & $68.06 \pm 9.16$ \\
\hline MRI-1 0.5\% w/w & $0.2-0.3$ & $1.68 \pm 0.86$ & $4.98 \pm 0.44$ & $19.52 \pm 0.43$ & $66.80 \pm 9.87$ \\
\hline MRI-2 0.1\% w/w & $0.5-1.2$ & $1.65 \pm 0.78$ & $4.58 \pm 0.36$ & $19.38 \pm 0.41^{*}$ & $67.97 \pm 13.02$ \\
\hline MRI-2 0.5\% w/w & $0.5-1.2$ & $1.65 \pm 0.78$ & $5.58 \pm 0.37$ & $20.24 \pm 0.39^{*}$ & $65.44 \pm 7.02^{*}$ \\
\hline
\end{tabular}

contrast had disappeared at week 8. Moreover, in this group an obvious region of newly formed bone could be localized inside, as well as outside the site of CPC injection (Fig. 4).

\subsection{Histology and micro CT for bone volume quantification}

In none of the histological sections an adverse tissue reaction or signs of severe inflammation were found. Micro CT observation as well as HE and EVG staining showed a uniform bone reaction in all groups, and combined information from histological slides and micro CT (Fig. 5a) allowed the location of the original defect site within the condyle. Upon light microscopical inspection, all defect areas appeared to be filled by newly formed trabecular bone. Bone marrow-like tissue was observed in between the bone voids and fibrotic tissue was absent. Despite the decalcification procedure, still traces of the implanted CPC were present in both CPC and MRI groups, whereas they could not be found in samples from the MRI/ BMP2 group.

The original $3 \times 3 \mathrm{~mm}$ defect area was selected to quantify the bone volume percentage. Eight weeks after implantation, the results showed significantly enhanced bone formation only in the presence of BMP-2, whereas no differences were detected between the other three groups (Fig. 5b).

a

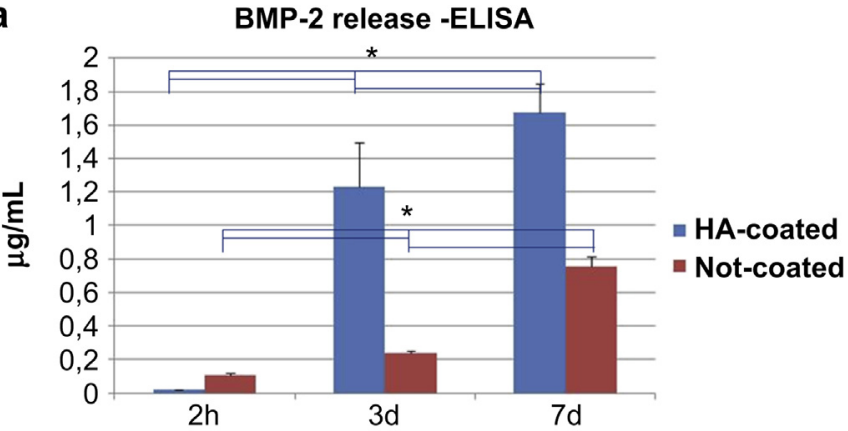

b

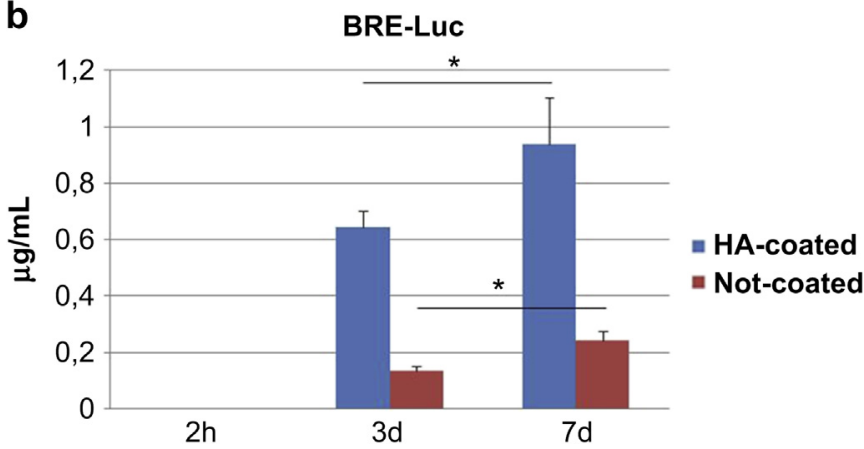

Fig. 3. In vitro BMP-2 release measured by a. ELISA and b. BRE-Luc assay. Both graphs compare the release from HA-coated beads against not coated beads. Results from both assays showed enhanced BMP-2 release in the presence of the coating. The BRE-Luc assay showed that, in the presence of the coating, the amount of bioactive released BMP-2 was relatively higher compared to the release in absence of coating.

\section{Discussion}

The present study aimed to test the feasibility of a theranostic agent, i.e. an agent which simultaneously is capable to enhance the MR bone contrast, as well as enhance the osteogenic properties of CaP bone cement. Both in vitro and in vivo assays were performed. The TA as used, was a nanocomposite of silica beads, in which an iron oxide core and a silane linker-modified and calcium phosphate coated surface for BMP-2 immobilization were structurally integrated. The main in vivo implantation results showed a long-term MR contrast enhancement, as well as improved osteogenic capacity, by means of new bone formation.

Theranostic agents are a class of imaging probes explored for the simultaneous visualization of drug delivery and therapeutic outcomes [8]. Conveniently, many imaging agents can be easily upgraded to theranostic agents. For example, iron particles, currently the most popular MR contrast agents [9], have been often selected for theranostic applications, as their surface coating allows straightforward chemical linkage and bioactive molecules loading [10]. In an initial study from our group, USPIOs were directly incorporated into CaP-based scaffolds, as enhancers of the implantto-bone contrast. Despite providing sufficient imaging contrast, this approach had many practical drawbacks. Mainly, the ultra small iron oxide particles (USPIOs) negatively affected the setting and mechanical properties of the injectable material [11]. Therefore, in a follow-up study, USPIOs were encapsulated into inert silica, with the purpose to reduce aspecific reactivity in the cement setting reaction [12]. In the present study, the same approach was used to synthesize two sets of silica particles, both encapsulating iron oxide, but differing by core size and iron particles-to-silica ratio. Besides the advantage of reducing unspecific reactivity, mesoporous silica has been extensively studied with regard to its applications for drug delivery and loading of bioactive molecules [13-15].

As first principal results of this study, the characterization of the particles and ex vivo MRI data were used for the selection of one TA composition for the final animal work. Although the MRI-2 showed a significant increase in final cement setting time, we regarded this effect of lesser importance, as the increase from 18 to 20 min would be irrelevant for clinical handling. In stead, the MRI-2 by visual inspection exhibited a region of hypointensity, which at the MRI settings used more closely resembled the original area of the CPCfilled defect. It is important though to realize that shape measurements with any iron-containing MRI contrast agent will always be irreliable, as such agents are always be susceptible to so-called blooming effects. This type of artifact indeed was seen at both MRI-1 and MRI-2. It would ideally be possible to perform quantitative assessments on this effect with phantom studies, combined with proper calibration of the image thresholding. Such quantification however was not the aim for the current work, where image settings were always kept constant.

After proper imaging contrast was achieved, we focused on the osteogenic protein. A recent study from Elhert et al. [16] sought to investigate the immobilization methods of BMP-2 on ceramic bone replacement materials. Only in the presence of the aminosilane 


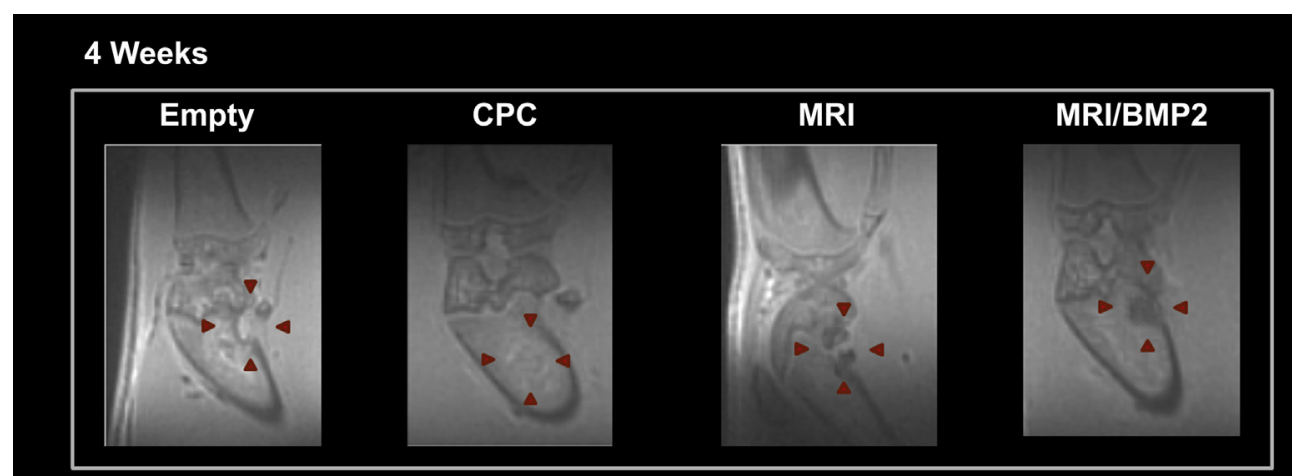

8 Weeks

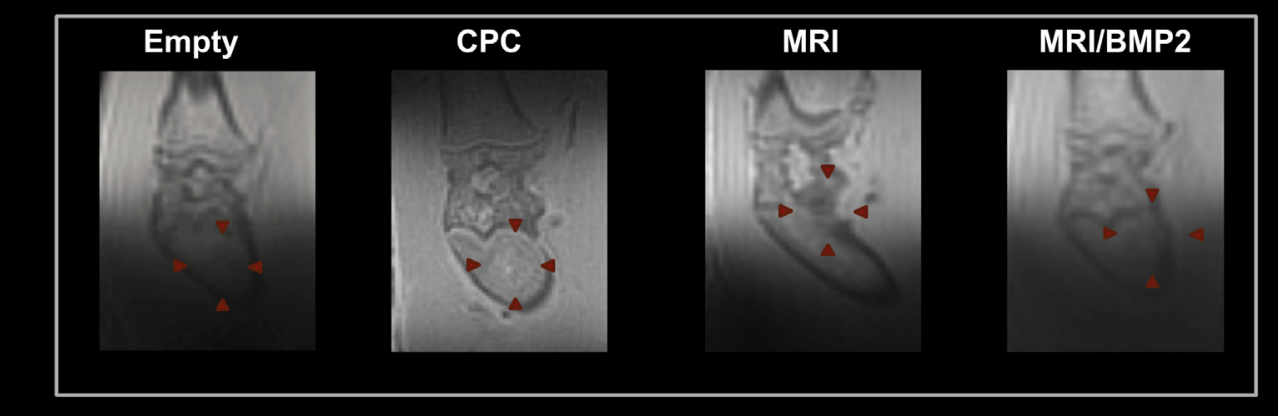

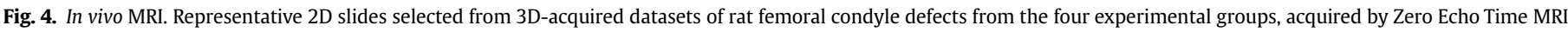

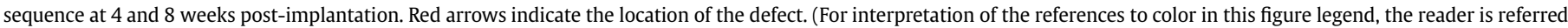
to the web version of this article.)

a
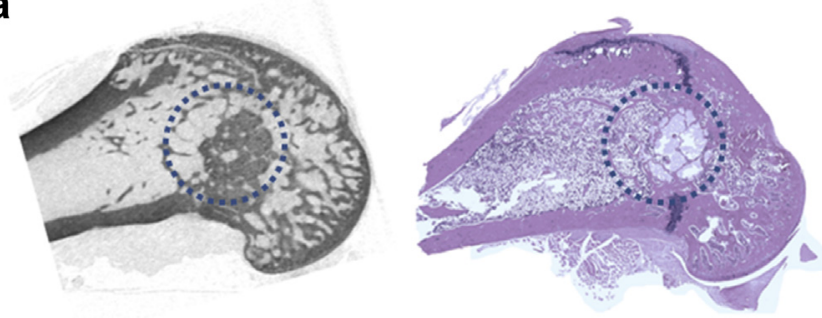

b

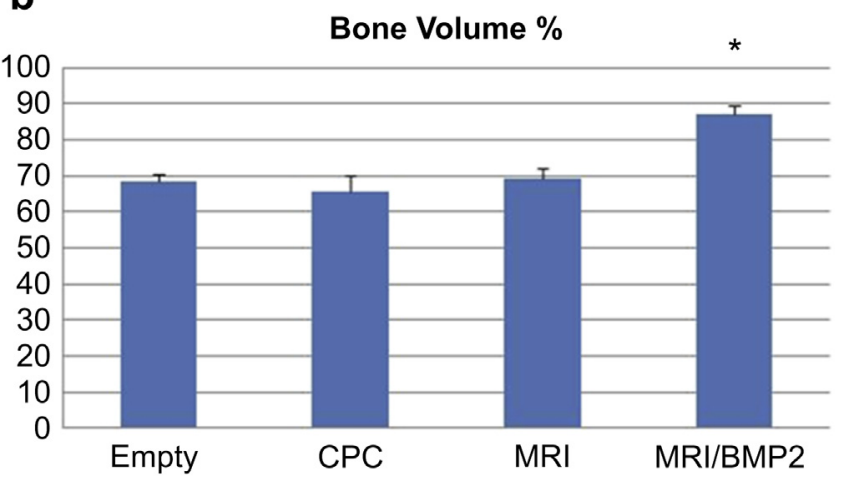

Fig. 5. Micro CT and histology for bone volume quantification. a. Qualitative $\mu \mathrm{CT}$ and histological evaluation. Representative $2 \mathrm{D}-\mu \mathrm{CT}$ and corresponding H\&E stained sections from the CPC group 8 weeks post-implantation. The dashed circle indicated the original defect area. b. Quantitative evaluation of bone formation. Bone formation was measured within the original defect area, in the four experimental groups, 8 weeks after implantation. Bone percentage in all groups was around $60-70 \%$, while the MRI/ BMP2 group showed a significantly enhanced bone formation $(P<0.05)$. linker notable amounts of BMP-2 could be immobilized. Considering these results, in the present study, the same approach was used to immobilize BMP-2 on the surface of the MRI-2 silica particles. Of course, also the amount of BMP-2 provided at the implant site is determining for its function [17-19], and furthermore appropriate amounts can vary among different scaffold materials. For CPCs ranges from 2 to $30 \mu \mathrm{g}$ have been investigated [20,21], while several studies report enhanced bone formation already at the lowest doses [22-24]. In the present study therefore a final concentration of $\sim 5 \mu \mathrm{g}$ per defect was adsorbed onto the beads and incorporated into each CPC scaffold.

The possibilities to further modulate BMP-2 release in terms of kinetics and concentration ranges, have been extensively explored. One option to modulate release is to provide the carrier with a coating. In the present study, the silica particles were coated by precipitated hydroxyapatite, following BMP-2 adsorption. The study of Boix et al. showed that BMP-2 has high affinity for hydroxyapatite, mainly influenced by the abundance of calcium or phosphate ions, especially at low pHs [25]. These results support the hypothesis that in our study, BMP-2 might have higher affinity for the coating rather than the functionalized silica support. It is therefore realistic to expect a fast release of the coating from the silica surface, together with the attached BMP-2. Based on the BRELuc assays results, upon release, the coating also contributed to preserve higher concentrations of bioactive BMP-2.

Finally, we tested in vitro the setting time and compressive strength of the CPC. Such handling properties are often overlooked but of critical interest to surgeons. It was shown that handling was not significantly affected by the incorporation of the TA, corroborating the data of our previous study [12]. The material handling remained acceptable within a range which still meets the clinical demands when repairing non-loading sites [24].

The TA-CPC was thereafter also tested in vivo, upon injection in a femoral condyle defect model in rats. The animal model is a well- 
established defect model for testing injectable as well as pre-set bone substitute materials $[26,27]$. The relatively easy surgical procedure, together with the easily accessible location for imaging procedures, makes this model optimal for the purposes of our study. Again corroborating our previous data [12], standard nonmodified CPC was not distinguishable from the surrounding bone tissue. In contrast, the TA-CPC remained detectable by MRI up to eight weeks post-implantation. However, in most samples from the MRI/BMP2 group, contrast was seen at 4 weeks, but no longer observable after 8 weeks. Such observation is not due to a decay of the generated signal, but rather indicative that $\mathrm{CPC}$ remodeling and degradation was accelerated by the activity of BMP-2. Moreover, the results of this group evidenced that the TA was released from the CPC upon its degradation, but not incorporated into the newly formed bone, as the contrast enhancement would still be detectable otherwise. This property makes the TA particularly attractive for longitudinal and material degradation studies. Furthermore, for these type of beads is has been described that upon release from the scaffold, they can be cleared through intestinal macrophages and, due to their size, renal filtration [28,29], overcoming toxic accumulation issues. Finally, also the histological evaluations proved that no traces of the implanted CPC could be retrieved in the MRI-BMP/2 group, supporting the notion that indeed the MR contrast disappearance 8 weeks post-implantation was solely due to the CPC scaffold degradation.

\section{Conclusions}

Multimodal and multifunctional theranostic probes are forming a cutting-edge technology, in which the advantages of both advanced imaging and therapeutic strategies can be combined. In the present study, we have described a bead-based formulation composed of an iron oxide core for MR contrast enhancement, embedded in a mesoporous silica matrix on which BMP-2 was immobilized. Our strategy allowed to overcome negative interference of the addition of a contrast agent to the biomaterial properties. Furthermore, bioactive BMP-2 could be efficiently released from the carrier-beads, leading to localized and effective bone regeneration. The described TA was shown to be suitable for longitudinal material degradation and bone healing studies.

\section{Disclosure statement}

No competing financial interests exist.

\section{Acknowledgments}

European Community's Seventh Framework Programme (MultiTERM, grant agreement no 238551). Natasja van Dijk, Vincent Cuijpers, Martijn Martens, Elly Vitters, Andor Veltien, Bianca Lemmers-van de Weem, and Kitty Lemmens-Hermans for technical assistance. Scanning electron microscopy and transmission electron microscopy were performed at the microscope imaging center (MIC) of the Nijmegen Centre for Molecular Life Sciences (NCMLS).

\section{References}

[1] Van de Watering FCJ, Molkenboer-Kuenen JDM, Boerman OC, van den Beucken JJJP, Jansen JA. Differential loading methods for BMP-2 within injectable calcium phosphate cement. J Control Release 2012;164:283-90.

[2] Mouriño V, Boccaccini AR. Bone tissue engineering therapeutics: controlled drug delivery in three-dimensional scaffolds. J R Soc Interface 2010;7:209-27.
[3] Weiger M, Stampanoni M, Pruessmann KP. Direct depiction of bone microstructure using MRI with zero echo time. Bone 2013;54:44-7.

[4] Prabhu P, Patravale V. The upcoming field of theranostic nanomedicine: an overview. J Biomed Nanotechnol 2012;6:859-82.

[5] Félix Lanao RP, Hoekstra JW, Wolke JG, Leeuwenburgh SC, Plachokova AS, Boerman OC, et al. Porous calcium phosphate cement for alveolar bone regeneration. J Tissue Eng Regen Med 2012 [Epub ahead of print].

[6] Lopez-Heredia MA, Sariibrahimoglu K, Yang W, Bohner M, Yamashita D, Kunstar A, et al. Influence of the pore generator on the evolution of the mechanical properties and the porosity and interconnectivity of a calcium phosphate cement. Acta Biomater 2012;8:404-14.

[7] Ehlert N, Hoffmann A, Luessenhop T, Gross G, Mueller PP, Stieve M, et al. Amino-modified silica surfaces efficiently immobilize bone morphogenetic protein 2 (BMP2) for medical purposes. Acta Biomater 2011;4:1772-9.

[8] Terreno E, Uggeri F, Aime S. Image guided therapy: the advent of theranostic agents. J Control Release 2012;161:328-37.

[9] Bulte JW, Kraitchman DL. Iron oxide MR contrast agents for molecular and cellular imaging. NMR Biomed 2004;17:484-99.

[10] Xie J, Lee S, Chen X. Nanoparticle-based theranostic agents. Adv Drug Deliv Rev 2010;62:1064-79.

[11] Sun Y, Ventura M, Oosterwijk E, Jansen JA, Walboomers XF, Heerschap A. Zero echo time magnetic resonance imaging of contrast-agent-enhanced calcium phosphate bone defect fillers. Tissue Eng Part C Methods 2013;19:281-7.

[12] Ventura M, Sun Y, Rusu V, Laverman P, Borm P, Heerschap A, et al. Dual contrast agent for computed tomography and magnetic resonance hard tissue imaging. Tissue Eng Part C Methods 2013;19:405-16.

[13] Shi X, Wang Y, Ren L, Zhao N, Gong Y, Wang DA. Novel mesoporous silicabased antibiotic releasing scaffold for bone repair. Acta Biomater 2009;5: 1697-707.

[14] Shi X, Wang Y, Varshney RR, Ren L, Zhang F, Wang DA. In-vitro osteogenesis of synovium stem cells induced by controlled release of bisphosphate additives from microspherical mesoporous silica composite. Biomaterials 2009;30: 3996-4005.

[15] Ehlert N, Mueller PP, Stieve M, Behrens P. Immobilization of alkaline phosphatase on mesoporous silica. Microporous Mesoporous Mater 2010;131:51-7.

[16] Ehlert N, Mueller PP, Stieve M, Lenarz T, Behrens P. Mesoporous silica films as a novel biomaterial: applications in the middle ear. Chem Soc Rev 2013;42: 3847-61.

[17] Chenard KE, Teven CM, He TC, Reid RR. Bone morphogenetic proteins in craniofacial surgery: current techniques, clinical experiences, and the future of personalized stem cell therapy. J Biomed Biotechnol 2012;2012:601549.

[18] Su Jiansheng, Xu Hongzhen, Sun Jun, Gong Xue, Zhao Hang. Dual delivery of BMP-2 and bFGF from a new nano-composite scaffold, loaded with vascular stents for large-size mandibular defect regeneration. Int J Mol Sci 2013;14: 12714-28.

[19] Epstein Nancy E. Complications due to the use of BMP/INFUSE in spine surgery: the evidence continues to mount. Surg Neurol Int 2013;4:S343-52.

[20] van de Watering FC, van den Beucken JJ, van der Woning SP, Briest A, Eek A, Qureshi H, et al. Non-glycosylated BMP-2 can induce ectopic bone formation at lower concentrations compared to glycosylated BMP-2. J Control Release 2012;159:69-77.

[21] Lee K, Silva EA, Mooney DJ. Growth factor delivery-based tissue engineering: general approaches and a review of recent developments. J R Soc Interface 2011;8:153-70.

[22] Kisiel M, Klar AS, Martino MM, Ventura M, Hilborn J. Evaluation of injectable constructs for bone repair with a subperiosteal cranial model in the rat. PLoS One 2013;8:e71683.

[23] Kisiel M, Ventura M, Oommen OP, George A, Walboomers XF, Hilborn J, et al, Critical assessment of rhBMP-2 mediated bone induction: an in vitro and in vivo evaluation. J Control Release 2012;162:646-53.

[24] Guo D, Xu K, Zhao X, Han Y. Development of a strontium-containing hydroxyapatite bone cement. Biomaterials 2005;26:4073-83.

[25] Boix T, Gómez-Morales J, Torrent-Burgués J, Monfort A, Puigdomènech P, Rodríguez-Clemente R. Adsorption of recombinant human bone morphogenetic protein rhBMP-2 onto hydroxyapatite. J Inorg Biochem 2005;99:1043-50.

[26] Schouten C, van den Beucken JJ, de Jonge LT, Bronkhorst EM, Meijer GJ, Spauwen $\mathrm{PH}$, et al. The effect of alkaline phosphatase coated onto titanium alloys on bone responses in rats. Biomaterials 2009;30:6407-17.

[27] Castellani C, Zanoni G, Tangl S, van Griensven M, Redl H. Biphasic calcium phosphate ceramics in small bone defects: potential influence of carrier substances and bone marrow on bone regeneration. Clin Oral Implants Res 2009;20:1367-74.

[28] Sato K, Yokosuka S, Takigami Y, Hirakuri K, Fujioka K, Manome Y, et al. Sizetunable silicon/iron oxide hybrid nanoparticles with fluorescence, superparamagnetism, and biocompatibility. J Am Chem Soc 2011;133:18626-33.

[29] Choi HS, Liu W, Misra P, Tanaka E, Zimmer JP, Itty Ipe B, et al. Renal clearance of quantum dots. Nat Biotechnol 2007;25:1165-70. 